\title{
Forecasting Demand for Automotive Aftermarket Inventories
}

\author{
Ovidiu DOBRICAN \\ West University of Timisoara \\ ovidiu.dobrican@feaa.uvt.ro
}

Management decisions regarding the resource allocation in the automotive aftermarket involves a good understanding of it. This includes a better understanding of the participants in this market, the supply chains, specificities products and demand for these products. A useful instrument to anticipate the latter is the use of simulation methods, one of them being the Monte Carlo method, which, in this paper, is used to create various scenarios of supply.

Keywords: Inventory Management, Aftermarket, Demand, Monte Carlo Simulation

1 Introduction

We can define the inventory as a physical stock of economic resources that are stored or reserved for a good functioning of related business. Inventories are required because, in general, a customer will not like to wait for a long time, until their commands were filled from a source or were produced.

On the other hand, maintaining inventory can protect against the seasonal price fluctuation of some raw material, because a buyer can procure a large quantity at good price and use it also when the price is high [1].

Inventory management also concerns about lead time, carrying costs, asset management, inventory forecasting, inventory valuation, inventory visibility, future inventory price, physical inventory, physical storage, quality management, replenishment, returned goods, obsolete goods and demand forecasting [2].

To maintain inventories involves the use of resources, so, it is necessary to introduce a set of policies and controls that establish and track levels of inventory and determine when stock should be refilled [3].

In addition, in automotive aftermarket domain, a large inventory could, also, attract more customers resulting increase in sale and profits.

For this purpose, we can use an inventory model based on Monte Carlo to determine the optimum inventory level in terms of safety stock and replenishment scenario. For this, the starting point is forecasting of demand which includes the prediction, projection or estimation of expected demand of the products over a specified future time period.

\section{Inventories in Automotive Aftermarket Domain}

2.1 Automotive Aftermarket Structure and Evolution

Aftermarket parts are an alternative of OEM (original equipment manufacturer) parts. These parts are produced by companies other than the original manufacturer but are made to fit and perform as well as the original. Aftermarket companies buy the rights to reproduce these parts. There are a variety of high quality aftermarket parts that can be purchased and live up to all the expectations of the original at a much lower price. In both cases, OEM and aftermarket parts, the part should perform the function it was designed for, so the car owner will decide which part to choose [4].

Over the years, supply chain in automotive aftermarket has gone through many transformations as we see in Figure 1, Figure 2 and Figure 3 consecutively.

Cash and carry retailers (discount shop selling a wide range of products) had an important role in aftermarket domain but, recently, they reduced their presence in this market, because of the need to allocate resources to other increasing competition sectors, like in food and clothing [5]. 


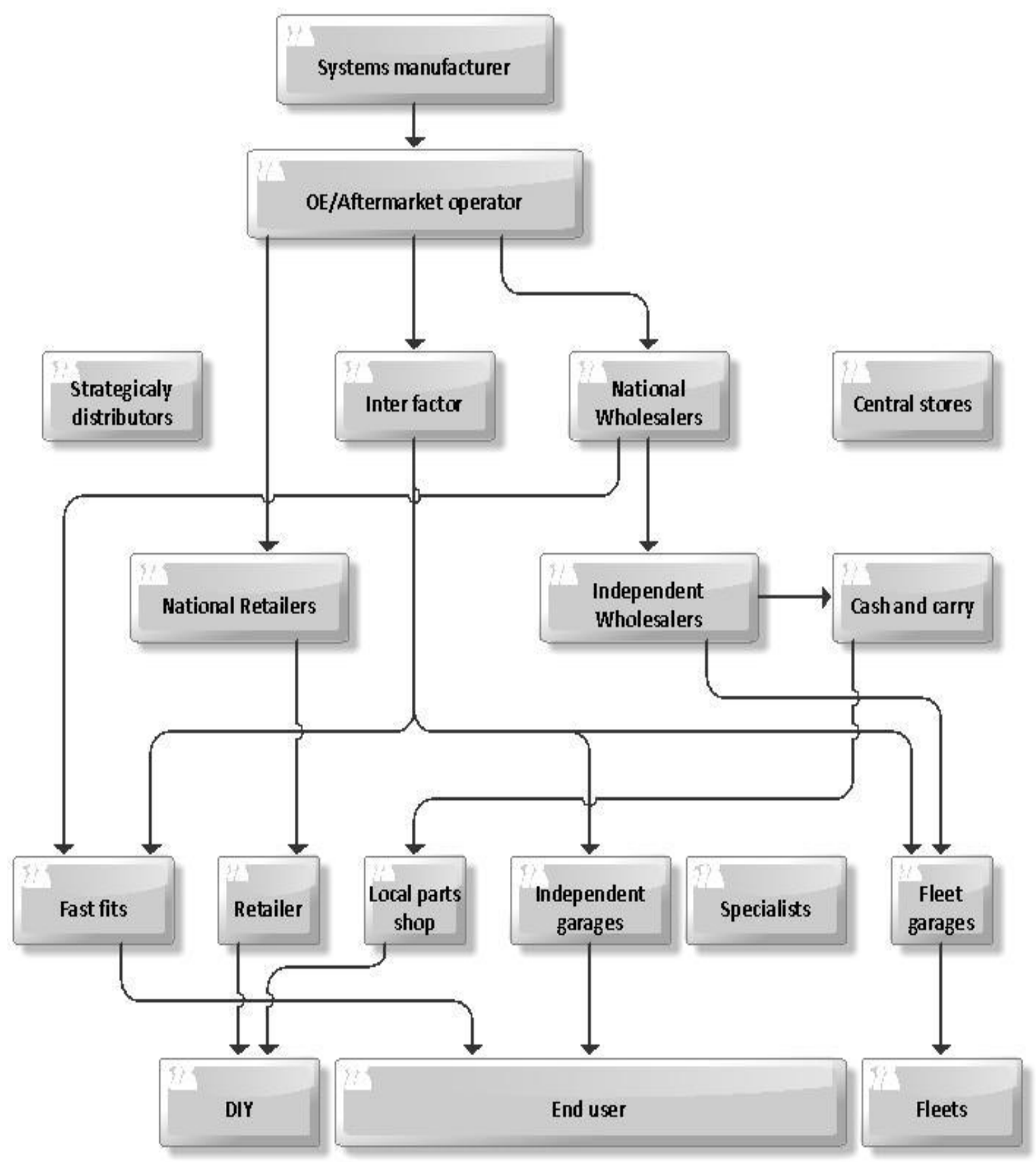

Fig. 1. Automotive aftermarket supply chain structure - version 1 (adapted [5])

National wholesalers, who used to rely on the original equipment (OE) manufacturers for a large proportion of their goods, are now serviced by Inter Factors (local retailers that deliver to point of use on very short lead-time) which are closer to the customer and can deliver goods to the point of use quicker. Also they have now only the role to serve independent wholesalers, as we see in Figure 2 and Figure 3.

National retailers have also moved away from OE supply in order to eliminate the need for large central stores (warehouses owned by national players). Instead these national retailers have opted for service from independent wholesalers at a local level resulting in better service time and reduced stock ownership [5]. 


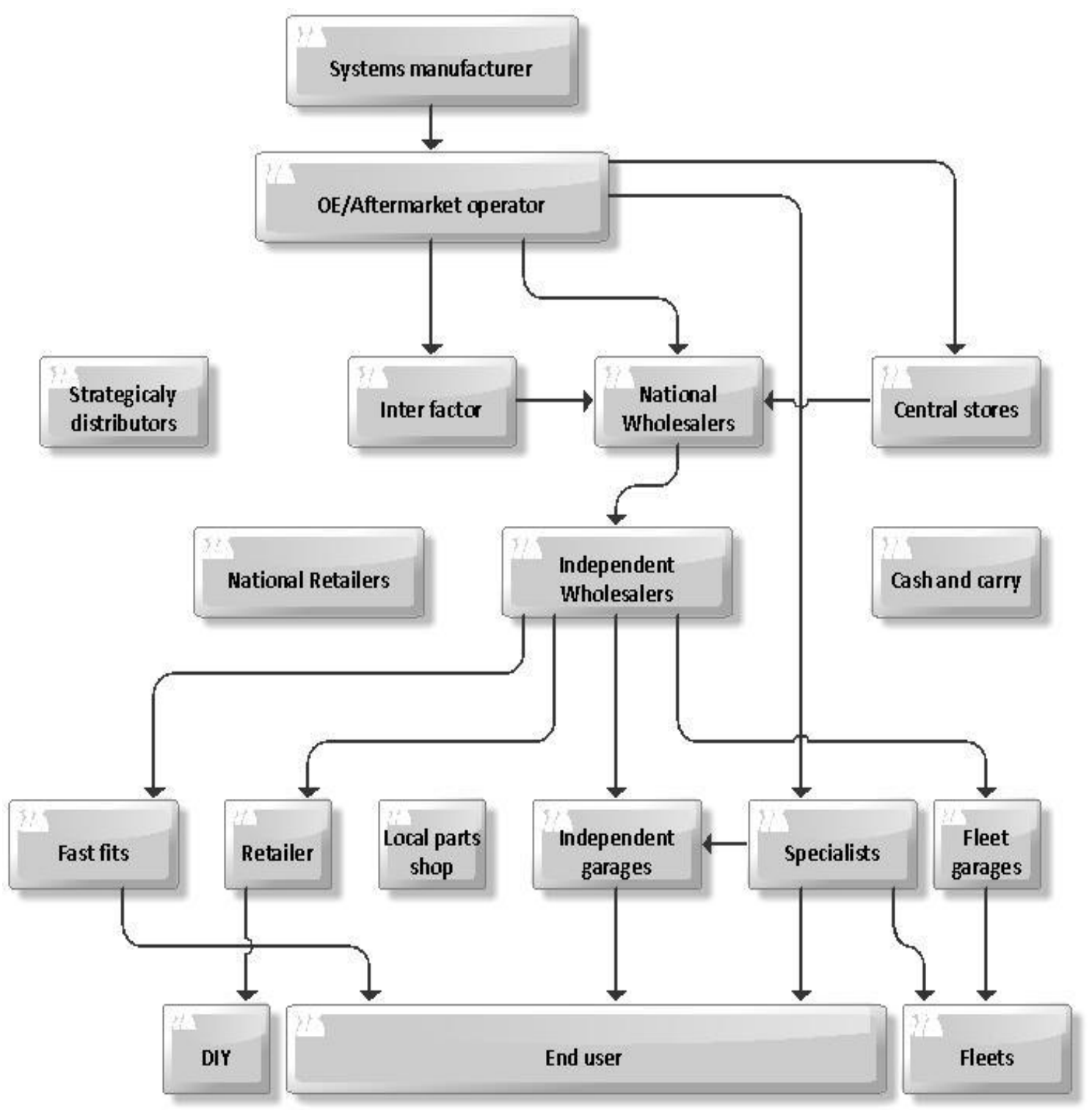

Fig. 2. Automotive aftermarket supply chain structure - version 2 (adapted [5])

Also, as we see in Figure 2 and Figure 3, the role of independent wholesalers increased with the decline of "Cash and Carry" organizations. These independent wholesalers have switched attention to fast fits, retailers, independent garages and fleet garages

Fast Fits (menu based service providers) have also evolved in a similar manner, moving towards more locally based suppliers. They increased their supply area of by including strategically distributors and even directly OE/Aftermarket operators in order to fulfil end users' needs.

Local parts shops have found it increasingly hard to win market share since many people prefer to deal directly with independent wholesalers. Their decline was also caused by disappearance of "Cash and Cary" stores in this market.

Specialists (providers of specialist parts and equipment) have increased in importance, in that they became a very fast connecting link between the OE/Aftermarket operators and the end users. By that, they bypass all intermediate levels, thus ensuring more rapid delivery to the final customer.

Consequently, to the growing number of specialists, independent garages began to lose market share. 


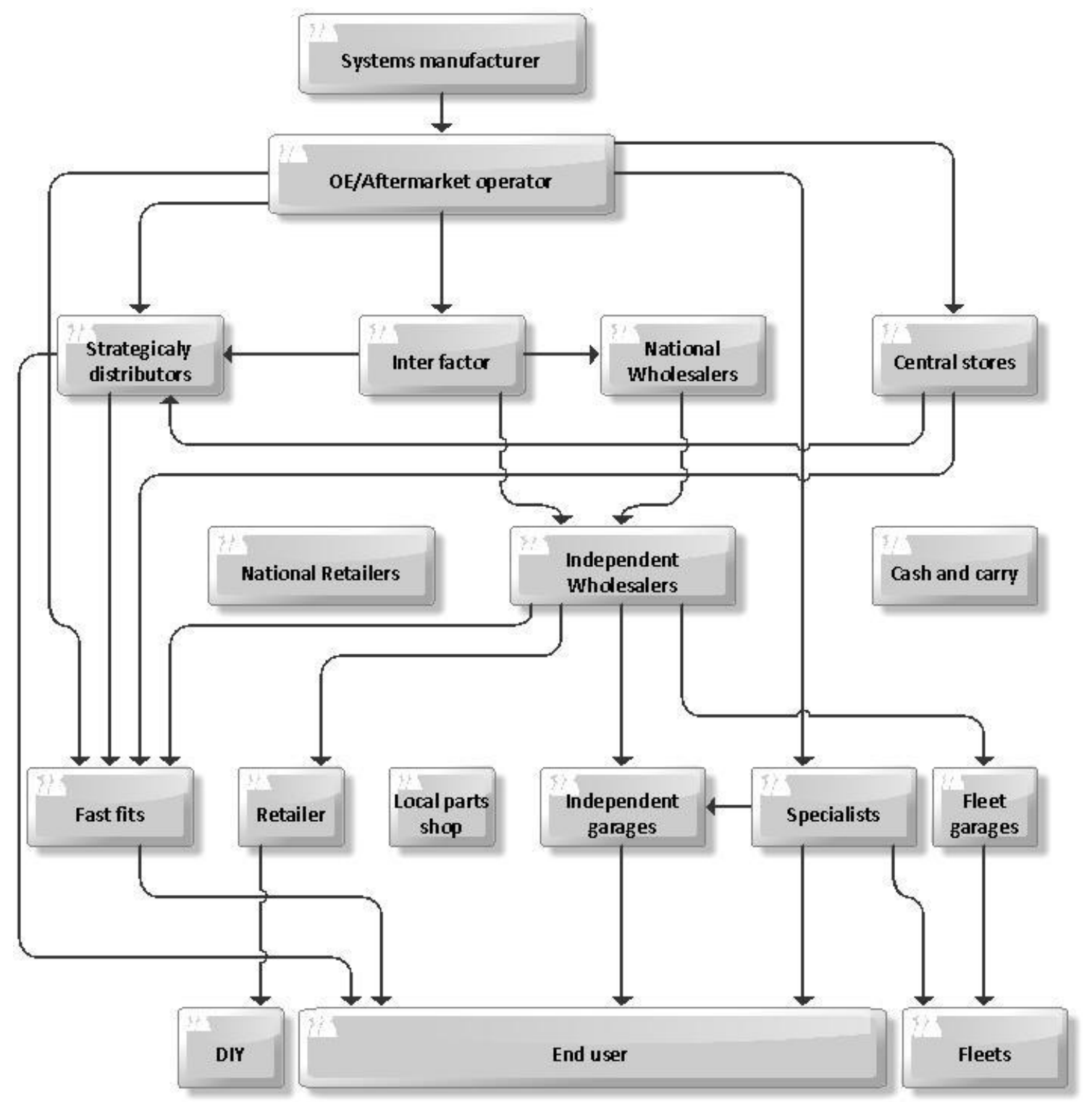

Fig. 3. Automotive aftermarket supply chain structure - version 3 (adapted [5])

The end users now have access to a wider range of suppliers like strategically distributors or specialist, as we see in Figure 3, [5].

\subsection{Reasons for Holding Inventories}

Taking into account [4], [6] and the particularities of automotive aftermarket domain, companies keep inventories for the following reason:

- To keep down productions costs. Because it is costly to set up machines, production should not be stopped as long as it is not necessary, in order to obtain low unit costs, but, it is necessary to establish a balance between these costs and the costs of holding stock;

- To help the production and distribution operations run more smoothly. Here, stock is held to "decouple" the two different activities;

- To avoid lack of stock. Growing demands increase the risk of shortages. This risk will be reducing by having safety stocks throughout the distribution channels (national or independent wholesalers, retailers) as we see in Figure 3. But, in this case, an important aspect is inventory visibility. This refers to the requirement for companies located throughout the supply chain, to deliver the latest and accurate data from in-stock inventory to in-transit inventory, and helps optimize supply chain process [7];

- $\quad$ To meet expected demand. It is necessary 
to have a buffer stock to cover the expected demand, especially for seasonal products like air springs, for example;

- To take account of variable supply (lead) times. A supplementary stock is necessary to cover any unexpected delivery delays from suppliers;

- To take advantage of the large orders size, by reducing order and shipment cost;

- To maintain independence of operations. The possible problems that can occur across the distribution channels require a buffer stock in order to maintain independence of the two operations, supply and delivery;

- To protect against price increases. Sometimes is useful to order large purchase to achieve quantity price savings and also to protect when expected price increases are;

- To provide customers with immediate service. It is essential in automotive aftermarket domain, to provide goods as soon as they are required, in order to increase customer confidence, and, by consequence, to increase the number of customers.

All these reasons are important to avoid under stocking and, by consequence, missed deliveries, backlogged orders, lost sales and unhappy customers.

\subsection{Costs and demand in aftermarket in- ventory domain}

An important role in decisions concerning the type and level of inventory cost plays. Taking into account the specificities of this market, according to those specified in [6], [8], [9] and [10], we can emphasize the following types of costs:

- Inventory carrying cost: capital cost (the largest component), storage space cost (rent, handling, heating, lightning), service costs (insurance, taxes), risk costs (obsolescence, damage, theft);

- Order cost - reviewing inventory stock levels, preparing purchase orders, checking and inspecting stock prior to placement in inventory, preparing and pro- cessing payments

- Shortage Cost - depends on how the company handles the problem. If the problem is solved only with a back-order, this cost is simple to quantify. The major problems appear when the customer's goodwill is affected. This penalty costs are more difficult to measure, as it is influenced by further losses of sales.

The other variables which taking into account on inventory decision making are:

- Lead - Time - it is the time between placing an order and its realization in stock. It can be deterministic or probabilistic. In studied domain, the lead-time is deterministic;

- Demand - it may be deterministic, when demand over a period is known, or probabilistic, when the demand over as period is uncertain but can be predicted by a probability distribution. Taking into account the specific aftermarket domain and those specified in [11], we emphasizes the several other classifications of demand:

$\circ$ Level of demand - is always measured in relative terms to your total inventory and it may be high (service parts - filters) or low (central units);

- Frequency of demand - it may be fast and, in general, with deterministic demand (tyres) or slow (car body parts);

- Patterns of demand - it may be stable, trend (upward or downward) or seasonality (like air springs for example);

- Product life cycle positioning - the five distinct phases in a product life cycle - launch, emerging, established, decline, withdrawal are less applicable in aftermarket area, due to the specialized nature of this market;

o Product classification - it refers to Parreto classification. According to this classification, $20 \%$ of the total number of items represent as much as $80 \%$ of the total turnover (A 
products), $30 \%$ of the total number of items represent only $15 \%$ of the total turnover (B products), and 50\% of the total number of items represent only $5 \%$ of the total turnover (C products). "A" items should receive a special attention in inventory control and in forecasting, but companies might decide to include " $\mathrm{C}$ " products in the "A category" if these items are strategically important to the business or critical to one of the company's strategic customers even if their absolute sales value is low [11].

It may be also independent or dependent demand, but in automotive aftermarket domain, we can consider that the demand is independent.

To determine the quantities of items that must be ordered, firms usually analyze their sales and market, using a variety of techniques, like customer surveys or forecasting.

\section{Demand forecasting and Monte Carlo simulation}

The key problem is to closely match supply and demand. According to [10], there are several ways to realize this:

- a supplier to have stock available for delivery at any time. This method maximizes sales revenues, but it is also expensive because of the cost of having inventory and the possibility of discounts at the end of the selling season

- use of flexible pricing. During heavy demand periods, prices can be raised to reduce peak demand. Price discounts can then be used to increase sales during periods with excess inventory or slow demand. This strategy can determine lost sales, stock outs, and thus cannot be considered a fair strategy to satisfying demand.

Managing demand is difficult because it is hard to forecast future consumer requirements accurately. Suppliers must be able to accurately forecast demand so they can produce and deliver the right quantities demanded by their customers in a timely and cost ef- fective fashion. Thus, it is imperative that suppliers along the supply chain find ways to better match supply and demand to achieve optimal levels of cost, quality and customer service to enable them to compete with other supply chains. Any problems that adversely affect the timely delivery of products demanded by consumers will have ramifications throughout the entire chain [10].

So, in order to realize a good inventory management, it is necessary to use forecasting. According to [12], "forecasting is a process of estimating a future event by casting forward past data. The past data are systematically combined in a predetermined way to obtain the estimate of the future". The goal of a good forecasting technique is to minimize the deviation between actual demand and the forecast [10].

Forecast the demand is also the key element in automotive aftermarket supply chain, from manufactures who need to know how much to produce to wholesalers and retailers who need to know how much to stock. In today's competitive business environment, collaboration (or cooperation and information sharing) between supply chains actors is the rule rather than the exception. The benefits of better forecasts are lower inventories, reduced stock outs, smoother production plans, reduced costs and improved customer service [10].

To realize a good inventory management, it can be use a model which may be deterministic - limited because it treats all parameters relating to future operations as certain, or probabilistic (stochastic) - considers uncertainty in demand and the delivery lead time. A variable is stochastic if its value cannot be specified in advance of observing it. [13]

To determine which version of the model to be applied, it starts with the analysis of the previous demand levels, evaluated at $n$ points in time, and calculation of average, standard deviation and coefficient of variation.

\footnotetext{
$N_{1}, N_{2}, \ldots, N_{n}-n$ points in time

$\bar{N}$ - average

$\sigma-$ standard deviation

$C_{v}-$ coefficient of variation
} 


$$
\begin{aligned}
& \bar{N}=\frac{1}{n} \sum_{i=1}^{n} N_{i} \\
& \sigma^{2}=\frac{1}{n-1} \sum_{i=1}^{n}\left(N_{i}-\bar{N}\right)^{2} \\
& \sigma=\sqrt{\sigma^{2}} \\
& C_{v}=\frac{\sigma}{\bar{N}}
\end{aligned}
$$

If $C_{v}<0.2$, i.e. have a low scattering values, models to be used are deterministic, since demand is sufficiently close to the average. If $C_{v}>0.2$, scattering demand values is quite high, the average is not a good demand's level, so the applied model is probabilistic.

In automotive aftermarket domain, demand's uncertainties require probabilistic inventory models. In these models the keyword is simulation.

When we use the word simulation, we refer to any analytical method meant to imitate a real-life system, especially when other analyses are too complex or too difficult to reproduce.

A Monte Carlo method is a technique that involves using random numbers and probability to solve problems. [14] The Monte Carlo method is just one of many methods for analyzing uncertainty propagation, where the goal is to determine how random variation, lack of knowledge, or error affects the sensitivity, performance, or reliability of the system that is being modelled. Monte Carlo simulation is categorized as a sampling method because the inputs are randomly generated from probability distributions to simulate the process of sampling from an actual population. [15]

The Monte Carlo method generates random values of a variable, by using:

- a generator of random numbers uniformly distributed in the interval $[0,1]$ and

- cumulated probability distribution associated to this random variable. [13]

We consider a stochastic variable $X$ with multiple possible values and $x_{i}$ a particular value of the variable $X$.

The probability that a value of the stochastic variable $X$ is equal to a certain value $x_{i}$ is denoted $p\left(X=x_{i}\right)=p\left(x_{i}\right)$.
The probability that the value of a stochastic variable $X$ is less than or equal to a certain value $x_{i}$ is called the cumulative distribution function or cumulated probability and is denoted $P\left(x_{i}\right)$.

$P\left(x_{i}\right)=p\left(X \leq x_{i}\right)$
$P\left(x_{i}\right)=\sum_{v \leq x_{i}} p(v) \quad$ for $-\infty \leq \mathrm{xi} \leq \infty$

having the property

$P\left(x_{i}\right) \leq 1$

Cumulative probability $P\left(x_{i}\right)$ is then, the sum of probability of values less than or equal to $x_{i}$.

For the distributions based on historical data or by direct measurement of stochastic values of variable, considering that these are in the number of $N$, for that variable $X$, we can obtain the following table (Table 1):

Table 1. Historical data or direct measure-

\begin{tabular}{|c|c|}
\multicolumn{2}{c}{ ments } \\
\hline $\begin{array}{c}\text { Value of the } \\
\text { variable } x_{i}\end{array}$ & $\begin{array}{c}\text { Frequency of } \\
\text { occurrence } f_{i}\end{array}$ \\
\hline$x_{1}$ & $f_{1}$ \\
\hline$x_{2}$ & $f_{2}$ \\
\hline$\cdots \cdots$ & $\ldots \ldots$. \\
\hline$x_{m}$ & $f_{m}$ \\
\hline
\end{tabular}

The application of Monte Carlo method involves several steps:

- to calculate probabilities and cumulative probabilities

$$
\begin{gathered}
p\left(x_{i}\right)=\frac{f_{i}}{\sum_{i=1}^{m} f_{i}} \\
P\left(x_{i}\right)=\sum_{k=0}^{i} p\left(x_{i}\right)
\end{gathered}
$$

Where:

$\sum_{i=1}^{m} f_{i}=N$

$$
p\left(x_{0}\right)=P\left(x_{0}\right)=0
$$

- associate random numbers intervals for each cumulative probability

The results can be synthesized in the Table 2 . 
Table 2. Determination of the random number intervals

\begin{tabular}{|c|c|c|c|}
\hline Value of the variable $x_{i}$ & Probability & Cumulated probability & $\begin{array}{c}\text { Random numbers in- } \\
\text { tervals }\end{array}$ \\
\hline$x_{1}$ & $p\left(x_{1}\right)$ & $P\left(x_{1}\right)=p\left(x_{0}\right)+p\left(x_{1}\right)$ & {$\left[P\left(x_{0}\right), P\left(x_{1}\right)\right)$} \\
\hline$x_{2}$ & $p\left(x_{2}\right)$ & $P\left(x_{2}\right)=P\left(x_{1}\right)+p\left(x_{2}\right)$ & {$\left[P\left(x_{1}\right), P\left(x_{2}\right)\right)$} \\
\hline$\ldots \ldots$ & $\ldots \ldots$ & & \\
\hline$x_{m}$ & $p\left(x_{m}\right)$ & $P\left(x_{m}\right)=P\left(x_{m-1}\right)+p\left(x_{m}\right)$ & {$\left[P\left(x_{m-1}\right), P\left(x_{m}\right)\right)$} \\
\hline
\end{tabular}

- generate a table of random numbers $u_{k}$, uniformly distributed on the interval $[0,1]$, using a specialized generator, such as RAND() function from Excel

- searching in Table 2, the interval $\left[P\left(x_{k-1}\right)\right.$, $\left.P\left(x_{k}\right)\right)$ which belongs $u_{k}$ number and write next to it, the simulated value $x_{k}$

- repeat the last two steps until we reach the desired volume of simulated data.

These values can be further used in the development of supply scenarios as we will emphasize in the case study.

By Monte Carlo method, the real process is replaced by an artificial process. To obtain best results, it is necessary that the random variables generated during simulation experiments to replicate as closely as possible, real random variable.

Therefore it can be established, for example, for average, a confidence interval calculated usually at $95 \%$.

Confidence interval for the average $1-\alpha$, where $\alpha$ is usually 0.05 , is:

$$
\left(\bar{x}-t_{\alpha / 2, N-1} * \frac{\sigma}{\sqrt{N}}, \bar{x}+t_{\alpha / 2, N-1} * \frac{\sigma}{\sqrt{N}}\right)
$$

where:

$t_{\alpha / 2, N-1}$ is obtained from the $t$ distribution tables.

$N$ is the number of simulated events

We can observe that the method is more pre- cise (narrower range) as the number of events is greater, i.e. $N^{1 / 2}$.

If, after $\mathrm{N}$ experiments, is obtained an average $M$ determined by the formula:

$M=\frac{1}{N} \sum_{i=1}^{N} v_{i}$

then the average of the variable $X$ could be anywhere in the range $(M-\Delta, M+\Delta)$, where:

$\Delta=\frac{2}{\sqrt{N}} \sqrt{\frac{\sum_{i=1}^{N}\left(v_{i}-M\right)^{2}}{N-1}}$

Therefore the question is, in general, in the Monte Carlo simulations, the number of procedures to be of the order of $10^{3}$.

\section{Case Study}

The studied company collaborates with major manufacturers or strategic distributors in particular from Germany. These vendors usually impose conditions related to lead-time, minimum order values, discounts, etc. Therefore it is necessary a harmonization of the values resulting from simulation with these conditions.

Based on demand recorded in the previous periods of time, we try to establish a supply simulated scenario for a product, using Monte Carlo method with initial stock 0 , as we can see in Figure 4 


\begin{tabular}{|c|c|c|c|c|c|c|c|c|c|c|}
\hline Cod prod & Per & Qty & Nr recd & Min & Max & $\begin{array}{c}\mathrm{Nmb} \\
\text { per }\end{array}$ & $\begin{array}{l}\text { Nmb per } \\
\text { cumul }\end{array}$ & $\begin{array}{c}\text { Probabilit } \\
\text { cumul }\end{array}$ & Intervals & Qty \\
\hline 44M/R4A.CV & 1 & 2 & 20 & 0 & 6 & 2 & 2 & 0,1 & {$[0,0,1)$} & $\mathbf{0}$ \\
\hline 44M/R4A.CV & 2 & 1 & & & & 4 & 6 & 0,3 & {$[0,1,0,3)$} & 1 \\
\hline 44M/R4A.CV & 3 & 3 & & & & 6 & 12 & 0,6 & {$[0,3,0,6)$} & 2 \\
\hline 44M/R4A.CV & 4 & 2 & & & & 3 & 15 & 0,75 & {$[0,6,0,75)$} & 3 \\
\hline 44M/R4A.CV & 5 & 4 & & & & 3 & 18 & 0,9 & {$[0,75,0,9)$} & 4 \\
\hline 44M/R4A.CV & 6 & 2 & & & & 1 & 19 & 0,95 & {$[0,9,0,95)$} & 5 \\
\hline 44M/R4A.CV & 7 & 6 & & & & 1 & 20 & 1 & {$[0,95,1]$} & 6 \\
\hline 44M/R4A.CV & 8 & 0 & & & & & & & & \\
\hline 44M/R4A.CV & 9 & 2 & & & & Avg & & 2,400 & & \\
\hline 44M/R4A.CV & 10 & 1 & & & & St dev & & 1,603 & & \\
\hline 44M/R4A.CV & 11 & 4 & & & & Coef var & & 0,668 & & \\
\hline 44M/R4A.CV & 12 & 3 & & & & & & & & \\
\hline 44M/R4A.CV & 13 & 2 & & & & & & & & \\
\hline 44M/R4A.CV & 14 & 1 & & & & & & & & \\
\hline 44M/R4A.CV & 15 & 5 & & & & & & & & \\
\hline 44M/R4A.CV & 16 & 3 & & & & & & & & \\
\hline 44M/R4A.CV & 17 & 1 & & & & & & & & \\
\hline 44M/R4A.CV & 18 & 4 & & & & & & & & \\
\hline 44M/R4A.CV & 19 & 2 & & & & & & & & \\
\hline 44M/R4A.CV & 20 & 0 & & & & & & & & \\
\hline
\end{tabular}

Fig. 4. Historical data

These intervals are established based on the We can observe in Figure 4, that lead-time imposed by the manufacturers or strategic distributors.

- $C_{v}>0.2$

- $A V G=2.4$

\begin{tabular}{|c|c|c|c|c|c|c|c|c|}
\hline $\begin{array}{c}\text { Random } \\
\text { gen }\end{array}$ & $\begin{array}{l}\text { Demand } \\
\text { simulat }\end{array}$ & purchase price & 2 & & & & & \\
\hline 0,1956751 & 1 & pre ad & $20,00 \%$ & & & & & \\
\hline 0,8488544 & 4 & value added & 0,4 & & & & & \\
\hline 0,620782 & 3 & selling price & 2,4 & & & & & \\
\hline 0,1056403 & 1 & initial stock & 0 & & & & & \\
\hline 0,7978384 & 4 & supply scenario & 2 & & & & & \\
\hline 0,5840981 & 2 & percent storage cost & $1,00 \%$ & & & & & \\
\hline 0,0685607 & 0 & & & & & & & \\
\hline 0,8809542 & 4 & per & stock bgn per & simul demand & stock end per & income & loss & storage cost \\
\hline 0,6236517 & 3 & 1 & 2 & 1 & 1 & 2,4 & 0 & 0,01 \\
\hline 0,754623 & 4 & 2 & 3 & 4 & 0 & 7,2 & $-0,4$ & 0 \\
\hline 0,8435883 & 4 & 3 & 2 & 3 & 0 & 4,8 & $-0,4$ & 0 \\
\hline 0,6711504 & 3 & 4 & 2 & 1 & 1 & 2,4 & 0 & 0,01 \\
\hline 0,0534109 & 0 & 5 & 3 & 4 & 0 & 7,2 & $-0,4$ & 0 \\
\hline 0,8950894 & 4 & 6 & 2 & 2 & 0 & 4,8 & 0 & 0 \\
\hline 0,2444503 & 1 & 7 & 2 & 0 & 2 & 0 & 0 & 0,02 \\
\hline 0,1687565 & 1 & 8 & 4 & 4 & 0 & 9,6 & 0 & 0 \\
\hline 0,337458 & 2 & 9 & 2 & 3 & 0 & 4,8 & $-0,4$ & 0 \\
\hline 0,7372483 & 3 & 10 & 2 & 4 & 0 & 4,8 & $-0,8$ & 0 \\
\hline 0,7205459 & 3 & 11 & 2 & 4 & 0 & 4,8 & $-0,8$ & 0 \\
\hline 0,6361801 & 3 & 12 & 2 & 3 & 0 & 4,8 & $-0,4$ & 0 \\
\hline 0,3150957 & 2 & 13 & 2 & 0 & 2 & 0 & 0 & 0,02 \\
\hline 0,3367517 & 2 & 14 & 4 & 4 & 0 & 9,6 & 0 & 0 \\
\hline 0,9274321 & 5 & 15 & 2 & 1 & 1 & 2,4 & 0 & 0,01 \\
\hline
\end{tabular}

Fig. 5. Simulation data

Also, we will consider value added, storage cost and shortage loss: (Figure 5)

- calculating value added as follows value added $=$ purchase price $*$ prc ad

- calculating a shortage loss as follows

Shortage loss $=$ value added $*$ (stock bgn per - stock end per)
- calculate a storage cost for remaining stock at the end of each period

Storage cost $=$ stock $*$ percent storage cost

We'll apply then, Monte Carlo method in 2 scenarios:

- Each order will be below average - 2 pieces - Figure 6 


\begin{tabular}{|c|c|c|c|c|c|c|c|c|}
\hline 0,5810361 & 2 & 97 & 8 & 1 & 7 & 2,4 & 0 & 0,07 \\
\hline 0,6963156 & 3 & 98 & 9 & 3 & 6 & 7,2 & 0 & 0,06 \\
\hline 0,2029074 & 1 & 99 & 8 & 4 & 4 & 9,6 & 0 & 0,04 \\
\hline \multirow[t]{17}{*}{0,1300423} & 1 & 100 & 6 & 4 & 2 & 9,6 & 0 & 0,02 \\
\hline & & 101 & 4 & 2 & 2 & 4,8 & 0 & 0,02 \\
\hline & & 102 & 4 & 3 & 1 & 7,2 & 0 & 0,01 \\
\hline & & 103 & 3 & 6 & 0 & 7,2 & $-1,2$ & 0 \\
\hline & & 104 & 2 & 2 & 0 & 4,8 & 0 & 0 \\
\hline & & 105 & 2 & 2 & 0 & 4,8 & 0 & 0 \\
\hline & & 106 & 2 & 3 & 0 & 4,8 & $-0,4$ & 0 \\
\hline & & 107 & 2 & 1 & 1 & 2,4 & 0 & 0,01 \\
\hline & & 108 & 3 & 1 & 2 & 2,4 & 0 & 0,02 \\
\hline & & & & & & & & \\
\hline & & & & & Income & 513,6 & & \\
\hline & & & & & Tot sim demand & 214 & & \\
\hline & & & & & Profit & 85,6 & & \\
\hline & & & & & Loss & $-15,6$ & & \\
\hline & & & & & Tot storage cost & $-1,74$ & & \\
\hline & & & & & & & & \\
\hline & & & & & Total & 68,26 & & \\
\hline
\end{tabular}

Fig. 6. Scenario with 2 pieces

- Each order will be above average - 3 pieces - Figure 7

\begin{tabular}{|c|c|c|c|c|c|c|c|c|}
\hline 0,6535663 & 3 & 97 & 53 & 2 & 51 & 4,8 & 0 & 0,51 \\
\hline 0,9809433 & 6 & 98 & 54 & 0 & 54 & 0 & 0 & 0,54 \\
\hline 0,9566919 & 6 & 99 & 57 & 1 & 56 & 2,4 & 0 & 0,56 \\
\hline \multirow[t]{17}{*}{0,3843368} & 2 & 100 & 59 & 1 & 58 & 2,4 & 0 & 0,58 \\
\hline & & 101 & 61 & 2 & 59 & 4,8 & 0 & 0,59 \\
\hline & & 102 & 62 & 2 & 60 & 4,8 & 0 & 0,6 \\
\hline & & 103 & 63 & 5 & 58 & 12 & 0 & 0,58 \\
\hline & & 104 & 61 & 5 & 56 & 12 & 0 & 0,56 \\
\hline & & 105 & 59 & 3 & 56 & 7,2 & 0 & 0,56 \\
\hline & & 106 & 59 & 6 & 53 & 14,4 & 0 & 0,53 \\
\hline & & 107 & 56 & 6 & 50 & 14,4 & 0 & 0,5 \\
\hline & & 108 & 53 & 2 & 51 & 4,8 & 0 & 0,51 \\
\hline & & & & & & & & \\
\hline & & & & & Income & 655,2 & & \\
\hline & & & & & Tot sim demand & 273 & & \\
\hline & & & & & Profit & 109,2 & & \\
\hline & & & & & Loss & 0 & & \\
\hline & & & & & Tot storage cost & $-32,89$ & & \\
\hline & & & & & & & & \\
\hline & & & & & Total & 76,31 & & \\
\hline
\end{tabular}

Fig.7. Scenario with 3 pieces

At the end of the experiment we'll emphasize net profit and stock's level for this product.

\section{Discussions}

As we said, previous data observation periods were established based on delivery times provided by large operators in the market. Our company must conform to these terms.

We will observe also, that in both simulated scenarios, profit is approximately the same, but the final stock is 2 respectively 51 , so the preferred scenario that with 2 pieces order.

But, in the scenario with 2 pieces could appear shortages, so a discussion can be made related to shortage cost.

Mathematically, it can be calculated by the formula:

Shortage loss $=$ value added $*($ stock bgn per - stock end per)

In fact, the loss could be much higher because it may lead to losing the customer.

For this, it is necessary to order more, at least at certain periods, to cover additional demand.

\section{Conclusions}

In this paper we analyzed structure of automotive aftermarket and how it has transformed over the years. Then we analyzed why it is important to hold inventories. The inventories has involves costs. So, we emphasized further the costs of holding stocks. 
To establish the level of these inventories, we used a mathematical models based on simulation. The presented model shows how Monte Carlo simulation model can be used to help managers to build an order scenario.

In terms of future directions, this model can be extended by testing various scenarios and include elements of what-if analysis.

Also, it can be extended to other scenarios of supply for all products provided by a manufacturer, to be able to make a "unified" stock order.

So, in conclusion, modeling provides an important support for decision making process in this dynamic and growing domain of automotive aftermarket, so integration of these elements in inventories management concepts is absolutely necessary.

The quality of the simulation, however, will be confirmed only by the way future customer requirements are covered, something that we will see in the future sales level and in number of new customers.

\section{References}

[1] S. Gor \& Soni,Operations Research, PHI Learning Pvt. Ltd., 2007

[2] http://en.wikipedia.org/wiki/Inventory, (March 20, 2013)

[3] F. R. Jacobs, R. B. Chase, Operations and Supply Chain Management: The Core. McGraw-Hill, 2008

[4] http://www.thepartsbin.com/oem_vs aftermarket.html, (March 22, 2013)

[5] J. Hammant, S.M. Disney, P. Childerhouse and M.M. Naim, "Modelling the consequences of a strategic supply chain initiative of an automotive aftermarket operation", International Journal of Physical Distribution \& Logistics
Management, Volume 29 (9):16, pp. 553 550, Emerald Publishing, Nov 1999

[6] A. Rushton, Ph. Croucher, P. Baker, The handbook of logistics and distribution management, $4^{\text {th }}$ Edition, Kogan Page Limited, 2010

[7] A. N. Zhang, M. Goh, F. Meng "Conceptual modelling for supply chain inventory visibility", International Journal Production Economics 133, pp. 578-585, Elsevier B.V., 2011

[8] D.M. Lambert and J.T. Mentzer, "Inventory Carrying Costs: Current Availability and Uses", International Journal of Physical Distribution \& Logistics Management, Vol. 12 (3), pp. 56 - 71, 1982

[9] J.J. Coyle, C.J. Langley, B.J. Gibson, R. Novack, E.J. Bardi, Supply Chain Management: A Logistics Perspective. Cengage Learning, 2008

[10] J. D. Wisner, K-C. Tan, G. K. Leong, Principles of Supply Chain Management, $3^{\text {rd }}$ edition, Cengage Learning, 2012

[11] C. Scott, H. Lundgren, P. Thompson, Guide to Supply Chain Management, Springer-Verlag Berlin, 2011

[12] K. C. Arora, Production and Operations Management. Firewall Media, 2004

[13] W. L. Dunn, J. K. Shultis, Exploring Monte Carlo methods, Elsevier B.V., 2012

[14] T. N. Srivastava, Business Research Methodology. Tata McGraw-Hill Education, 2011

[15] J.W. Wittwer. (March 23, 2013) Generating Random Numbers in Excel for Monte Carlo Simulation, Available http://www.vertex42.com/ExcelArticles/ $\mathrm{mc} /$ GeneratingRandomInputs.html, June $1,2004$.

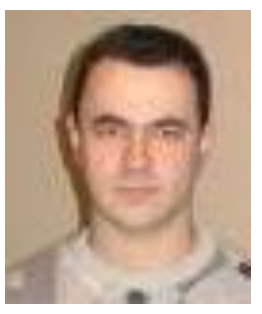

Ovidiu DOBRICAN is Teaching Assistant at Faculty of Economics and Business Administration at the West University of Timişoara and a $\mathrm{PhD}$ student in Business Information Systems at Babeş-Bolyai University of ClujNapoca. His main research areas are: DSS domain and collaborative systems. 